INÉS ARREDONDO

\title{
INÉS ARREDONDO Y EL MÉXICO DE LOS AÑOS SESENTA*
}

\author{
Claudia Albarrán**
}

Inés Arredondo (Culiacán 1928, México 1989) pertenece a la llamada Generación del Medio Siglo ${ }^{1}$ y, particularmente, a lo que se ha denominado el Grupo de la Revista Mexicana de Literatura, integrado por escritores como Tomás Segovia, Huberto Batis, Juan García Ponce, Juan Vicente Melo, Salvador Elizondo y José de la Colina, entre otros, que no sólo desarrollaron en México una obra creativa propia sino una labor crítica sobre distintos campos artísticos (teatro, cine, pintura, música, poesía, novela, cuento, ensayo) y un importante papel dentro del ámbito de la traducción. Esta labor creadora y crítica abrió nuevos caminos a la literatura mexicana, a sus posibilidades temáticas y estilísticas, y a una concepción del quehacer literario basada, fundamentalmente, en las nociones de calidad y universalidad.

En términos generales, el perfil de la generación a la que Inés Arredondo perteneció puede dibujarse a partir de varios aspectos: 1) La adopción de una postura contraria a ciertas tendencias nacionalistas

* El título original de este texto es: Inés Arredondo, la generación del medio siglo y su labor cultural en el México de los años sesenta, reducido por razones de espacio.

** Centro de Lenguas, ITAM.

${ }^{1}$ El término fue utilizado por Enrique Krauze (en "Cuatro estaciones de la cultura mexicana”, Caras de la historia, 1983, México, Joaquín Mortiz, p. 146) para englobar a las personas nacidas entre 1921 y 1935. 
CLAUDIA ALBARRÁN

de los años cuarenta, sustentada en el cuestionamiento de los presupuestos de la Revolución Mexicana y en la denuncia de las promesas revolucionarias incumplidas por parte del gobierno mexicano; 2) el cosmopolitismo, gracias al cual se fomentó y enriqueció una labor cultural con pocos precedentes en la historia nacional; 3) el pluralismo, que implicó la apertura de sus miembros al quehacer cultural y literario de otros países; 4) el apoyo de sus integrantes a otros jóvenes intelectuales y escritores tanto nacionales como extranjeros, quienes mostraron a la sociedad mexicana de los años sesenta otros rumbos y puntos de vista sobre el quehacer literario y cultural de México; 5) la participación en distintas instituciones culturales, como el Centro Mexicano de Escritores, y en distintas dependencias de la Universidad Autónoma de México; 6) una actitud crítica ante la cultura en general y ante algunas instituciones en particular, ejercida en diversas revistas del país -como Universidad de México, Revista Mexicana de Literatura, Cuadernos del Viento, S. Nob y La Palabra y el Hombre, entre otras-, y en los suplementos “México en la Cultura” (del periódico Novedades) y "La Cultura en México" (de la revista Siempre!); y 7) el apoyo recibido de diversas editoriales, como la Imprenta Universitaria de la UNAM, Ediciones Era, Empresas Editoriales, Editorial Joaquín Mortiz, Fondo de Cultura Económica y la editorial de la Universidad Veracruzana, por sólo citar algunas.

En síntesis, podemos decir que los miembros de esta generación no sólo compartieron los mismos intereses y anhelos, una misma vocación crítica y una decidida voluntad de hacer -lo que les permitió establecer fructíferos canales de comunicación y las bases de una larga amistad que, más tarde, daría como resultado su constitución como grupo- sino que, junto a esos intereses y voluntades afines, "hubo también una serie de instituciones y publicaciones literarias que, en gran medida, promoverían y facilitarían su integración. ${ }^{2}$

Sin duda, una la de las instituciones más importantes para los miembros de esta generación fue el Centro Mexicano de Escritores.

${ }^{2}$ Armando Pereira, La Generación de Medio Siglo, 1997, México, Instituto de Investigaciones Filológicas, UNAM, p. 30. 
INÉS ARREDONDO

Su antecedente fue el Mexican Writing Center, institución fundada por Margaret Shedd en 1951, que al principio no otorgaba incentivos económicos sino que funcionaba como una especie de taller en el que los escritores adscritos escuchaban críticas de especialistas sobre sus trabajos, los cuales se publicaron en el primero y único número de la revista Portafolio, escrita en inglés. Como tal, lo que entonces y, aún hoy, conocemos como el Centro Mexicano de Escritores nació ese mismo año por iniciativa de la propia Shedd, quien le propuso al Director de Humanidades de la Fundación Rockefeller, Charles Fahrs, la idea de estimular, mediante la otorgación de becas, la creación literaria de escritores jóvenes. Para llevar a cabo su proyecto, Shedd contrató como responsable de la promoción de las becas (también conocidas como "Becas Rockefeller”) a Felipe García Beraza, que al inicio se encargó de buscar y elegir al primer Consejo Literario del Centro, el cual quedó integrado por Alfonso Reyes, Julio Torri y Agustín Yáñez. Ese mismo año se establecieron las bases del concurso, y Alfonso Reyes -entonces Presidente del Consejo Literario- dio la noticia de la fundación a los medios informativos y culturales del país.

La primera convocatoria se publicó a mediados de 1951 y el monto de las becas iba de 16,500 a 20,000 pesos anuales, dependiendo del estado civil de los becarios. A mediados de la década de los sesenta, esta política económica fue sustituida por otros criterios: para los escritores jóvenes o que sólo habían publicado un solo libro, el monto de las becas era menor al que se otorgaba a escritores reconocidos y con una obra más vasta. A cambio del apoyo económico, los becarios tenían que asistir semanalmente a las reuniones, las cuales se realizaban todos los miércoles en las instalaciones del Centro y a las que acudían también los miembros del Consejo Literario para dar sus comentarios y asesorar los trabajos de los escritores adscritos al Centro.

Si al principio el Centro Mexicano de Escritores fue auspiciado en su totalidad por la Fundación Rockefeller, pocos años después se fueron incorporando a él distintos patrocinadores mexicanos que aportaron sumas iguales a las que la Fundación desembolsaba. A la larga, el apoyo de destacados hombres de negocios como Carlos Prieto y de 


\section{CLAUDIA ALBARRÁN}

otros empresarios y empresas mexicanas tanto públicas como privadas permitirían que el Centro abandonara el patrocinio de la fundación y se constituyera en una institución mexicana independiente.

Durante sus inicios, el Centro también dio cabida a becarios norteamericanos. Para ello, Shedd nombró a un representante estadounidense, el crítico Hershell Brickell, que fue contratado por la fundación para dar sus opiniones sobre las solicitudes de los candidatos de esa nacionalidad. Sin embargo, a mediados de los años sesenta, el Centro suspendería el otorgamiento de becas a norteamericanos debido a que, según García Beraza: "Fue un error, porque tanto los norteamericanos como los mexicanos estaban en formación. Poco podían aprender unos de otros. Además, existía la barrera verdaderamente infranqueable del idioma." 3 Desde entonces, y ya bajo la asesoría intelectual de Juan Rulfo y Juan José Arreola, el Centro acogería exclusivamente a jóvenes escritores mexicanos.

Para darnos una idea del apoyo que le brindó el Centro a los escritores de la Generación del Medio Siglo, basta enumerar los nombres y las fechas en las que algunos de ellos recibieron becas: Jorge Ibargüengoitia (1954-1955 y 1955-1956), Tomás Segovia (1954-1955 y 19551956), Juan García Ponce (1957-1958 y 1963-1964), Inés Arredondo (1961-1962), ${ }^{4}$ Salvador Elizondo (1963-1964 y 1966-1967) y José Emilio Pacheco (1969-1970).

A excepción de Inés Arredondo -quien en una entrevista confiesa que sólo solicitó la beca porque necesitaba el dinero y que los relatos que escribió durante ese año fueron 'abortos' porque nunca ha sido capaz de escribir un cuento al mes- ${ }^{5}$ y de García Ponce -quien

${ }^{3}$ Manuel Núñez Nava, "El pan de cada día” (entrevista a Felipe García Beraza), en Casa del Tiempo, n 11, julio 1981, p.18.

${ }^{4}$ Al igual que Inés, durante la promoción 1961-1962 recibieron la beca Vicente Leñero, Gabriel Parra Ramírez, Jaime Agusto Shelley, Miguel Sabido y los norteamericanos Frederick Griscom y Daniel Eckereley.

${ }^{5}$ En Mauricio Carrera, "Me apasiona la inteligencia” (entrevista a Inés Arredondo), Universidad de México, n 467, diciembre, 1989, p. 69, ella dice: "Fue ése un año perdido. Perdido porque soy incapaz de escribir 
INÉS ARREDONDO

renunció a la beca la segunda vez que se le otorgó y desde entonces ha mantenido una postura crítica hacia el Centro-, ${ }^{6}$ los demás coinciden en señalar los beneficios económicos e intelectuales que esta institución les brindó. La opinión de Salvador Elizondo, expresada con

un cuento al mes. Todos los cuentos que hice durante la beca fueron abortos, cuentos echados a perder. En realidad no debí haberla solicitado, si lo hice fue por dinero (...) porque escritor Tomás y escritora yo (bueno, pseudoescritora, porque no escribía), y con tres hijos, no nos alcanzaba nunca el dinero. La beca ayudó. Me dio la oportunidad de no trabajar y de dedicarle las mañanas a mis hijos, y las tardes, y de contratar una niñera que los cuidara mientras yo escribía o me ponía a leer.” Y agrega: "La crítica de la señora Shedd era muy rara. La de Ramón Xirau era buena pero al principio no me entendía. En cuanto a los demás becarios, nos hacíamos pedazos los unos a los otros. Era una manera de lucirse. Después nos íbamos a tomar un café y nos sincerábamos: 'Lo que te dije no era cierto, pero había que criticar'. (...) Shedd tenía una visión creo que muy norteamericana de la literatura, una visión que no era la más apropiada para juzgar lo que hacíamos nosotros, los becarios mexicanos. Un criterio que no nos ayudaba y que, incluso, nos estorbaba. Trataba de clasificarnos. Por ejemplo, de algunos de mis cuentos decía: 'parece una balada', cosa que, por supuesto, a mí no me parecía y me hacía encender de enojo.”

${ }^{6}$ En la entrevista que Margarita García Flores realizó a los directivos, becarios y ex-becarios con motivo del veinteavo aniversario del Centro Mexicano de Escritores, La Cultura en México, n 495, 4 de agosto de 1971, p. XII, García Ponce afirma: “Me es difícil siquiera recordar qué es el Centro. Para mí es un sitio totalmente fantasmal que no me interesa en lo absoluto. No le veo ninguna relación con nada que sea importante dentro de la literatura. Hace ocho años tuve una beca y renuncié a ella, porque en general tanto los sistemas como las disciplinas que consideraba necesarias al escritor se me hacen lo contrario totalmente de las exigencias que la creación plantea para cualquiera que desee escribir de verdad. Desde entonces no sé nada del Centro ni me importa: Ahora no se me ocurriría renunciar a una beca, ni siquiera solicitarla. Me parece que es una institución burocrática, que sirve para que unos ilustres inútiles devenguen un sueldo y tengan una relación ligera con la literatura. El Centro tiene tanta relación con la literatura como la Secretaría de Recursos Hidráulicos.” 


\section{CLAUDIA ALBARRÁN}

motivo del veinteavo aniversario del Centro, sintetiza la importancia que esta institución tuvo para los poetas, dramaturgos, novelistas, ensayistas y cuentistas de esta generación y para otros muchos escritores de nuestro país: "Me parece laudable la labor que hace el Centro, aunque sólo fuera porque es la única institución de su género. Un estímulo de tipo económico para un joven escritor, es muy importante. Aunque lo que se nos da no sea tampoco una cantidad fabulosa, pero cualquier cantidad que se le pague, es mejor y es un estímulo mayor que el de simplemente tenerlo escribiendo sin guía.”7

Por si la opinión de Elizondo no bastara para dar cuenta del papel preponderante que desempeñó el Centro en la promoción de nuestra literatura desde la década de los cincuenta, basta citar los títulos de algunos de los libros que vieron la luz gracias a las becas Rockefeller: Pedro Páramo, La región más transparente, Balún Canán, Farafeuf, Morirás lejos y La señal, entre muchos otros. ${ }^{8}$

Además del apoyo otorgado por el Centro, los miembros de la Generación del Medio Siglo tuvieron también una participación definitiva en la Universidad y en especial en la Coordinación de Difusión Cultural de la UNAM, dependencia que Jaime García Terrés Chávez dirigió de 1953 a 1965 y que fue fundamental para la formación tanto profesional como intelectual de estos jóvenes; de allí nacerían (o renacerían), distintos proyectos culturales, como el movimiento Poesía en Voz Alta (que dio inicio en 1956), la Casa del Lago (fundada en 1959), Voz Viva de México (que también comenzó ese año reuniendo en fonogramas a los más importantes escritores de nuestro país en los que se grabarían algunos relatos de los miembros de esta generación, como ‘La Sunamita’, de Inés Arredondo, y ‘Tajimara’, de García Ponce), y la revista Universidad de México.

\footnotetext{
${ }^{7}$ Ibid., p. X.

${ }^{8}$ Actualmente, el Centro Mexicano de Escritores cuenta con un archivo que contiene algunos de los proyectos, trabajos y primeros borradores de éstas y otras obras que los escritores se comprometieron a escribir durante su período como becarios.
} 
INÉS ARREDONDO

Respecto a Poesía en Voz Alta, cabe decir que en sus comienzos no fue un movimiento teatral, sino un grupo integrado por escritores, músicos, pintores, cantantes y actores jóvenes. Aunque los especialistas en el tema aún siguen discutiendo si la propuesta inicial vino de García Terrés o del dramaturgo Héctor Mendoza, podemos decir que la idea original fue organizar una serie de lecturas de poesía, para lo cual se buscó la participación de Octavio Paz y de Juan José Arreola; ellos fueron los primeros directores literarios del grupo y más tarde se les sumarían Antonio Alatorre y Margit Frenk (como consejeros literarios del Siglo de Oro español y como actores y cantantes), Alfonso Reyes, María Luisa Mendoza, Elena Garro, Carlos Fuentes, León Felipe, Diego de Meza, Sergio Fernández, José de la Colina y Juan García Ponce, entre otros escritores.

Para realizar el proyecto, se propuso escenificar la poesía y darle un espacio poético al teatro. Así pues, mientras Paz terminaba de escribir La hija de Rappaccini (una de las piezas que integró el segundo programa de Poesía en Voz Alta), Arreola armó el primer programa, compuesto por las siguientes obras: Égloga IV, de Juan de la Encina, La farsa de la casta Susana, de Diego Sánchez de Badajoz, y cuatro de García Lorca: La doncella, el marinero y el estudiante, El paseo de Buster Keaton, Quimera y El niño y el gato. De esta selección -mezcla de lo más antiguo del teatro español con la vanguardia surrealista del teatro de Lorca-surgieron las primeras características de Poesía en Voz Alta, ${ }^{9}$ planteadas por Arreola en el programa de presentación de esta inicial puesta en escena: La primera intención del movimiento era volver a los orígenes del teatro para despojarlo de cualquier artificio innecesario, es decir, llegar a la esencia del teatro, a la palabra hablada.

Se sumaron también el goce lúdico, la introducción de elementos inesperados que rompían con la solemnidad y la rigidez del teatro nacional, predominantemente realista durante esa década; se creó una escenografía y un vestuario poco usuales para la dramaturgia nacional

${ }^{9} \mathrm{Al}$ respecto, véase el número monográfico dedicado a Poesía en Voz Alta en la revista Universidad de México, n 473, junio, 1990. 
CLAUDIA ALBARRÁN

y, con la participación de músicos, pintores y artistas, se logró algo que -para muchos- significó el nacimiento del teatro experimental mexicano (el cual, según varios críticos, había tenido como único antecedente en México al Teatro Ulises, que estuvo animado por Antonieta Rivas Mercado y el grupo de los Contemporáneos).

Además, Poesía en Voz Alta fue el punto nodal para la creación de un lenguaje autónomo, paralelo e independiente del texto dramático, que significó el nacimiento de lo que hoy se conoce como lenguaje de la puesta en escena. Otras de sus características fueron acentuar el movimiento escénico, el trabajo vocal y corporal y/o la gesticulación de los actores para determinar el ritmo de la puesta en escena; subrayar la importancia de la composición plástica antes que la historia contada; incorporar a la escena el sketch, el music-hall, la carpa, la pantomima, la danza, el ballet y la música; poner énfasis en la dirección de los montajes. En síntesis, hacer del teatro un espectáculo múltiple, un espacio libre y experimental que permitiera a los artistas intervenir como autores, con todas sus posibilidades creativas e imaginativas.

A partir de este primer programa que fue presentado en el teatro El Caballito, el grupo se transformó en movimiento teatral; se logró montar un total de ocho programas en los que muchas veces se combinaba música, artes plásticas, la puesta en escena de piezas teatrales tanto vanguardistas como medievales o de los Siglos de Oro español y otros elementos escenográficos y de vestuario novedosos.

Desde el quinto programa (octubre de 1957), cuando José Luis Ibáñez tomó el lugar de Héctor Mendoza, el montaje fue sólo de obras unitarias, como Asesinato en la catedral, de T. S. Eliot; Las criadas, de Jean Genet o Electra, de Sófocles. El octavo y último programa, cuyo estreno fue el 27 de septiembre de 1963, marcó el fin de Poesía en Voz Alta, aunque muchos de sus integrantes siguieron reuniéndose y participando en los distintos eventos que se organizaban en la Casa del Lago y en otras dependencias universitarias.

Los primeros cuatro programas de Poesía en Voz Alta fueron auspiciados por la UNAM; los siguientes tres corrieron a cargo de diversas instituciones privadas y la última producción, cuyo escenario fue la 
INÉS ARREDONDO

Casa del Lago, de nueva cuenta estuvo auspiciada por la UNAM. Algunas puestas en escena incluyeron la participación de directores literarios como Arreola o Paz; otras, incluían musicalización, ya fuera de Joaquín Gutiérrez Heras, Leonardo Velázquez o Raúl Cosío; los programas contaron con la participación de artistas plásticos, como Juan Soriano, Héctor Xavier o Leonora Carrington, que se encargaron de la escenografía o el vestuario y que, a partir de entonces, colaborarían también -junto con otros artistas plásticos- con dibujos, grabados y viñetas en varias de las revistas y suplementos culturales que ya hemos mencionado.

Si desde el punto de vista de la dramaturgia nacional Poesía en Voz Alta significó un cambio radical en cuanto a lo que hasta ese momento venía haciéndose en el terreno del teatro mexicano, el movimiento también tuvo varias repercusiones en los miembros de la generación que estudiamos: gracias a dicho movimiento, la mayoría de estos escritores pudo asistir a diversos espectáculos y entablar relaciones con músicos, bailarines, poetas, artistas plásticos y dramaturgos antes desconocidos o poco conocidos por ellos. De hecho, Poesía en Voz Alta marcó la pauta de las reuniones y actividades que -pocos años más tarde y durante la dirección de Tomás Segovia y de Juan Vicente Melose llevarían a cabo en la Casa del Lago, lugar que también logró conjugar y dar rienda suelta a los múltiples intereses de artistas e intelectuales del país mediante la realización de eventos en los que se combinaba pantomima, música, danza, lectura de poemas, cine y exposiciones de pintura.

El primer director de la Casa del Lago fue Juan José Arreola, quien se hizo acompañar de Alberto Híjar (encargado de comentar las exposiciones de pintura), Miguel González Avelar (que cumplía las funciones de subdirector y publicaba un boletín semanal en el que se anunciaban los eventos de la Casa del Lago), Lourdes Compeán (responsable de la realización de distintas actividades culturales) y Juan José Gurrola (encargado de dirigir las lecturas de poesía y, más tarde, las sesiones de teatro leído). 


\section{CLAUDIA ALBARRÁN}

Durante la inauguración oficial (que se llevó a cabo el 15 de septiembre de ese año), se realizó una exposición de obras maestras del Renacimiento; sobre el lago del Bosque de Chapultepec se colocó un escenario flotante que sirvió de tablado para la presentación de la Escuela de Danza de la Unidad Artística y Cultural del Bosque, encabezada por Josefina Lavalle; y Gurrola y Arreola, subidos en una panga, recitaron fragmentos de la 'Suave patria’ de López Velarde.

Meses más tarde, las actividades se multiplicaron: hubo lecturas de poesía, presentaciones de grupos corales, audiciones de música clásica, funciones de cine, y los jardines de Chapultepec sirvieron de escenario a grupos folklóricos y otras manifestaciones populares. A partir de 1960 se organizaron mesas redondas abiertas al público en las que se trataban problemas sociales o artísticos con toda libertad. En el campo de la literatura se organizó un ciclo de conferencias titulado 'La nueva generación', con charlas sobre la obra de jóvenes escritores y artistas plásticos, entre los que se encontraba la gran mayoría de los miembros de la Generación del Medio Siglo.

Al inicio de 1961, Nabor Carrillo dejó su puesto de rector de la Universidad y su lugar lo ocupó Ignacio Chávez. García Terrés continuó en la jefatura de Difusión Cultural y Arreola cedió su lugar a Tomás Segovia, el primer marido de Inés Arredondo, quien se hizo cargo de Casa de Lago hasta 1963, continuando el proyecto de su amigo con la ampliación de las actividades -que antes sólo se realizaban durante el fin de semana- a toda la semana. Durante las tardes se abrieron diversos talleres artísticos y literarios impartidos por algunos miembros de la generación. Por ejemplo: el taller de ‘Iniciación a la literatura’ estaba a cargo de Juan Vicente Melo y el de ‘Iniciación a la poesía’ era impartido por Tomás Segovia. Se creó un ciclo de conferencias titulado 'Nuestro tiempo', en el que participaron creadores y artistas de la generación, como De la Colina, Pacheco y Elizondo. Se dio un gran impulso a la música de jóvenes artistas y se organizó una serie de eventos titulada 'Nueva música de México'.

Durante el período de Tomás Segovia como director destaca el papel que la Casa del Lago dio al teatro. Siguiendo con la veta abierta 
INÉS ARREDONDO

por Poesía en Voz Alta, se llevó a escena La hija de Rappaccini, de Octavio Paz, se estrenó Bajo el bosque blanco de Dylan Thomas -traducida por Pixie Hopkins y Juan José Gurrola (quien también la dirigió)- y se estrenó una obra de Tomás Segovia titulada Zamora bajo los astros, que dirigió José Luis Ibáñez.

A principios de 1963 -y debido al viaje de Tomás Segovia e Inés Arredondo a Montevideo- García Terrés nombró a Juan Vicente Melo responsable de la Casa del Lago. Durante su período como director (1963-1966), éste promovió distintas actividades importantes para la década, entre las que destacan la exposición ‘Juan Soriano y el teatro’, compuesta por los trabajos realizados por el pintor durante su participación en Poesía en Voz Alta; los seminarios en los que colaboraron los miembros del taller Carlos Chávez y el ‘Grupo Nueva Música’; un espectáculo de Gurrola compuesto por música de Jazz y poemas de Paz; el homenaje a Luis Cernuda; las conferencias literarias tituladas 'Los grandes personajes de la literatura', que impartieron los miembros de la generación. Juan Guerrero -quien durante la década de los sesenta se encargaría de llevar a la pantalla grande algunos relatos de los integrantes de la generación, como "Mariana” de Inés Arredondoorganizó los ciclos de cine, y se llevaron a escena las siguientes obras: Woyseck, de George Büchner (dirigida por Héctor Mendoza), La moza del cántaro, de Lope de Vega (dirigida por José Luis Ibáñez), y La cantante calva, de Ionesco (con escenografía de Gurrola).

Además de Poesía en Voz Alta y del proyecto cultural Casa del Lago, García Terrés reanimó también una de las publicaciones que no sólo fue fundamental para la década, sino, en especial, para la formación de los jóvenes escritores e intelectuales de la Generación del Medio Siglo: la revista Universidad de México. La publicación iniciada en 1930 con la dirección del dramaturgo Julio Jiménez Rueda, había mudado varias veces de título y de director, incluso había dejado de aparecer durante algunos años, reunía materiales diversos: desde antropología hasta física, desde literatura hasta astronomía, siempre acompañados de largos calendarios que informaba sobre las actividades del mes en la Universidad. 


\section{CLAUDIA ALBARRÁN}

Fue García Terrés quien, bajo la etiqueta ‘Nueva época’ y con una nueva numeración, dio vida a una revista que -a decir de algunos críticos- no ha alcanzado a la fecha el nivel de calidad y fama que tuvo durante esos años. Lo que sin duda sobresale de la declaración de principios que acompañó al primer número de esta época fue su interés por dar al público calidad informativa, lo cual implicaba contar con un grupo de colaboradores que se hiciera cargo de las notas y comentarios sobre las distintas actividades artísticas: cine, teatro, libros, espectáculos, arquitectura, artes plásticas. Se trataba de hacer de la cultura un ente 'vivo', de ofrecer "puntos de vista que [revelaran] la actitud crítica y vigilante del público más sensible a su recepción”, además de "ser un vehículo de intercambio cultural entre la Universidad y otras instituciones nacionales y extranjeras”.

Las propuestas de García Terrés tuvieron una inmediata acogida entre los miembros de la generación a la que Inés perteneció, quienes, si bien no ingresaron a la revista en 1953, irían incorporándose paulatinamente a ella durante la dirección de García Terrés. Pero no sólo porque les significaba un canal para la publicación de sus materiales, sino porque exigía de ellos una constante renovación y actualización de sus conocimientos culturales tanto de México como del extranjero y, simultáneamente, porque requería de una actitud verdaderamente crítica respecto al quehacer artístico.

Entre 1958 y 1965, las secciones dedicadas al cine, teatro, libros, música y artes plásticas (que habían nacido desde los inicios de esta nueva época) fueron cobrando mayor espacio e importancia en la revista. Además, la constancia con la que se publicaban las colaboraciones de algunos miembros de la generación los hizo especialistas de ciertas áreas, algunas nunca antes estudiadas por ellos en forma sistemática, pero que respondían a sus intereses. Así, Juan García Ponce (quien también utilizaba en la revista el pseudónimo de Jorge del Olmo) se dedicó durante varios años a la crítica de artes plásticas; José de la Colina se ocupó de los comentarios sobre cine, sección que compartía con Jomi García Ascot y Emilio García Riera, entre otros; Juan Vicente Melo colaboró con bastante frecuencia en la sección de música y danza; 
INÉS ARREDONDO

José Emilio Pacheco tenía una sección titulada 'Simpatías y diferencias’; Carlos Valdés, Tomás Segovia y los escritores anteriormente mencionados publicaron ahí reseñas de libros y colaboraron con notas y críticas en la famosa 'Feria de los días'. El diseño de la revista primero corrió a cargo de Miguel Prieto y de Vicente Rojo después, quienes -junto con otros pintores de prestigio, como Leonora Carrington, Pedro Coronel y Juan Soriano (que también colaboraron con ellos en la ilustración de los artículos y las notas que ahí se publicaban) le imprimieron a Universidad de México un sello artístico particular.

Entre los jefes o secretarios de redacción pertenecientes a esta generación, y que colaboraron con García Terrés durante su período como coordinador de Difusión Cultural, se encuentran Emmanuel Carballo y Juan García Ponce, futuros responsables de la Revista Mexicana de Literatura; José Emilio Pacheco, encargado de la sección "Ramas Nuevas”, de la revista Estaciones; Juan Vicente Melo, director de la Casa del Lago; Carlos Valdés, quien publicaría junto con Huberto Batis la revista Cuadernos del Viento (este último estaba a cargo de la Dirección General de Publicaciones de la UNAM y de la Imprenta Universitaria, y de 1965 a 1970 fue director de la Revista de Bellas Artes).

Tomás Segovia, futuro director de la Revista Mexicana de Literatura y de la Casa del Lago, nunca formó parte del Consejo de redacción de Universidad de México, pero su presencia fue permanente: en ella publicó poemas, ensayos y traducciones, además de que sirvió de punto de contacto entre escritores de fama internacional, quienes le hacían llegar sus materiales para ser traducidos y publicados en la revista.

Por su parte Inés Arredondo, además de publicar sus primeros cuentos en la revista Universidad de México ${ }^{10}$ y de colaborar frecuentemente con reseñas de teatro y comentarios sobre libros, trabajaba en el Departamento de Información y Prensa Universitaria -que se localizaba en la Torre de Rectoría, en CU, y que también albergaba a la Dirección de Difusión Cultural, a la revista Universidad de México y

${ }^{10}$ En ella publicó los siguientes relatos: 'El membrillo' (1957), 'Estar vivo’ (1961) y ‘Los inocentes’ (1976). 


\section{CLAUDIA ALBARRÁN}

a la Imprenta Universitaria. Como ella, muchos otros colaboradores de la revista y miembros de esta generación desempeñaban también diversos cargos universitarios. Tal fue el caso de José de la Colina, quien manejaba los cine clubs, o de Juan José Gurrola, que en ese entonces era el responsable de la televisión y del teatro universitarios.

Por si esto fuera poco, los integrantes de esta generación colaboraron también en otros suplementos y revistas culturales del país, como $L a$ Palabra y el Hombre, que dirigía Sergio Galindo; S. Nob, a cargo de Elizondo y García Ponce; 'México en la Cultura' (del periódico Novedades) y 'La Cultura en México’ (de la revista Siempre!), suplementos dirigidos por Fernando Benítez de 1959 a 1961 el primero, y de 1962 a 1972 el segundo; la citada revista Cuadernos del Viento, fundada por Batis y Valdés, y la Revista Mexicana de Literatura, que no sólo fue el medio de consolidación de los miembros de la Generación del Medio Siglo, sino cuyo título ha servido a los críticos para identificar a ese otro grupo minoritario de escritores al que también perteneció Inés Arredondo y que -como ya dijimos- se conoce como el 'Grupo de la Revista Mexicana de Literatura'.

Ahora bien, ¿cuáles fueron los motivos, los postulados, los intereses que sirvieron de punto de contacto entre los jóvenes que crearon la Revista Mexicana de Literatura? ¿Quiénes la integraron? ¿Por qué? Las respuestas más claras a estas preguntas las encontramos en la serie de entrevistas que Sergio González Levet ${ }^{11}$ realizó a los miembros del grupo y, en particular, en las páginas de la propia revista.

La publicación fue fundada por Carlos Fuentes y Emmanuel Carballo en 1955, con el propósito de ser un medio de difusión cultural abierto a las manifestaciones literarias del país, pero, sobre todo, a las letras internacionales, como una forma de contrarrestar la entonces creciente tendencia de la cultura mexicana hacia el nacionalismo oficial. Su título resulta, pues, significativo en la medida en que establece una clara oposición respecto a los propósitos de la Revista de Literatura

${ }^{11}$ En Letras y opiniones, 1980, Xalapa, Veracruz, Punto y Aparte. 
INÉS ARREDONDO

Mexicana que Antonio Castro Leal había dirigido en 1940 y cuyo corte y contenido habían sido eminentemente nacionalistas.

Dos años después de su fundación, los primeros directores de la Revista Mexicana de Literatura la abandonarían en razón de otros intereses, dejándola a cargo de Antonio Alatorre y Tomás Segovia, quienes -de alguna forma- sustentaron la fama e importancia que la publicación llegó a tener en los años siguientes y hasta 1965, fecha en la que dejó de salir al público. Su desaparición por un año (1958) y el cambio de directores marcó una nueva época que trajo consigo modificaciones en el comité de colaboradores, compuesto por Rubén Bonifaz Nuño, Rosario Castellanos, Augusto Monterroso, Ernesto Mejía Sánchez, Jorge Portilla, Emma Susana Speratti Piñero, Luis Villoro y Ramón Xirau. Sin embargo, antes de finalizar la década de los cincuenta, Antonio Alatorre viajó al extranjero y cedió su lugar a Juan García Ponce, quien durante dos años compartió con Segovia el cargo de director de la publicación.

En 1962, Segovia quedó como único responsable y García Ponce pasó a integrar un nuevo Consejo de redacción, junto con los escritores José de la Colina, Isabel Fraire, Jorge Ibargüengoitia y Juan Vicente Melo. Este cambio en la mesa directiva también trajo consigo el ingreso de Rita Murúa como responsable de la publicidad y de la administración y, a partir de 1963 y hasta 1965, García Ponce ocupó el cargo de director, debido a que Inés y Tomás viajaron a Uruguay para tratar de superar su crisis matrimonial. No obstante el viaje y la separación definitiva, ambos siguieron colaborando con la publicación y Segovia continuó como miembro del Consejo de redacción hasta que la revista dejó de publicarse.

Inés Arredondo comenzó a colaborar regularmente desde 1959, ${ }^{12}$ cuando su marido tomó el puesto de director. Pero lo que nos extraña de

${ }^{12}$ En ella publicó cinco de sus mejores cuentos: ‘La señal’, que inauguró la nueva época de la revista en 1959, 'La Sunamita', 'La casa de los espejos’ (ambos en 1961), ‘Canción de cuna’ (1964) y ‘Mariana’, que significativamente coincidió con el cierre de la revista en 1965. 


\section{CLAUDIA ALBARRÁN}

este dato es que, si bien tuvo una participación fundamental en ella (corregía los textos, armaba los números, asistía a las reuniones para discutir qué materiales se publicarían, etcétera), su nombre no aparece en la lista de los miembros del consejo de redacción. En la conversación que González Levet sostuvo con ella a propósito de la Revista Mexicana de Literatura, afirma al respecto: "es curioso, yo siempre estuve metida en la revista, pero como sombra: las reuniones eran en casa de Tomás y mía, y yo sí votaba y todo, pero mi nombre no aparecía en la revista: mesas de redacción iban y mesas de redacción venían y a mí me tocaba corregir planas, corregir galeras, seleccionar material y todo eso". ${ }^{13}$

Grosso modo, podemos decir que la política editorial de la revista consistía en ser un medio de expresión y difusión de la literatura tanto nacional como extranjera; esta política se mantuvo durante la nueva época y hasta el final, pero con el ingreso de Tomás Segovia y de Juan García Ponce a la dirección se hizo hincapié en que el requisito fundamental para la publicación de los textos fuera la calidad literaria de los materiales, se tratara de escritores jóvenes o de intelectuales consagrados.

34 La Revista Mexicana de Literatura rechazó toda actitud nacionalista, chauvinista, en virtud de un cosmopolitismo y un universalismo tomados, en gran medida, de otras revistas mexicanas anteriores -como Contemporáneos (fundada décadas atrás por el grupo de escritores del mismo nombre que, sin duda, representaron para ellos un ejemplo a seguir tanto artística como intelectualmente ${ }^{14}$ ), Hijo Pródigo y Taller,

${ }^{13}$ En Sergio González Levet, op. cit., p. 46.

${ }^{14}$ Como muestra de la predilección que los integrantes del grupo tenían por los Contemporáneos, basta decir que Inés hizo su tesis sobre Jorge Cuesta para obtener el título de Maestría en Letras (con la cual se graduó en 1980) y que escribió la biografía de Gilberto Owen, publicada bajo el título “Apuntes para una biografía de Gilberto Owen” en el número monográfico titulado “Homenaje Nacional a los Contemporáneos" (Revista de Bellas Artes, nº 8 , noviembre, 1982), en el que casi todos los miembros de su generación participaron con artículos. 
INÉS ARREDONDO

que había dirigido Octavio Paz- en las que se concebía a la literatura como un quehacer sin fronteras ni nacionalidades. De hecho, Octavio Paz fue uno de los mentores intelectuales más importantes de Universidad de México y, de alguna manera, continuó siéndolo también en la Revista Mexicana de Literatura: había comenzado a colaborar con algunos miembros de la generación desde 1957, les había 'hecho el honor' de darles algunos de sus poemas para su publicación e incluso les conseguía textos de escritores europeos de reconocido prestigio que, sin su solicitud, quizá no hubieran colaborado en ninguna de las dos revistas.

Pero la presencia de Paz en la vida de los jóvenes de esta generación no sólo se reduce al número de colaboraciones que tuvo en Universidad de México o en la Revista Mexicana de Literatura, ya que en la obra de creación de la mayoría de estos jóvenes, los libros de Paz tuvieron también una influencia notable; en especial, el capítulo titulado 'La revelación poética’ de El arco y la lira (publicado en 1956), en el que Paz se refiere al acto poético como una revelación de lo sagrado, como un salto a la otra orilla del río, y a los sentimientos tan paradójicos y contradictorios que ese salto motiva en quienes lo hacen posible a través de la palabra; nociones todas que, de alguna manera marcaron la concepción que tanto Inés como su generación tenían del quehacer literario y que funcionan en su obras narrativas como núcleo central para elaborar las historias.

Además del criterio universalista de la Revista Mexicana de Literatura, en ella también "se trataba -explica Arredondo- de recordar esas pequeñas obras que están a la vera de la literatura, que no son las que abren los horizontes de la literatura, pero que hacen sin embargo una literatura” ${ }^{15}$ Entre sus características destaca -además de la difusión y la traducción de textos de Pavese, Musil, Mann, Joyce, Sade y Miller, entre otros (que no sólo eran autores preferidos del grupo, sino que también tuvieron una influencia determinante en sus respectivas obras), y de escritores extranjeros poco difundidos o incluso desconoci-

${ }^{15}$ En Sergio González Levet, op. cit., p. 59. 
CLAUDIA ALBARRÁN

dos para las letras mexicanas de entonces (como Denise Levertov, Yves Bonnefoy, Hermann Broch, Herbert Marcuse o Keith Botsford)- la preocupación de sus miembros por ejercer una labor realmente crítica hacia la cultura y en particular la literatura. Labor que pudo llevarse a cabo debido a que, para entonces, algunos de los miembros del grupo ya habían alcanzado con las revistas Universidad de México y con los suplementos ‘México en la Cultura’ y 'La Cultura en México’, entre otros, un cierto prestigio no sólo como creadores, sino como críticos de los distintos campos del quehacer cultural.

Aunque en cada entrega de la revista generalmente se combinaban ensayos, poesía, ficción y crítica, en la mayoría de los números se publicaban traducciones de autores extranjeros; también se le dio apoyo a escritores latinoamericanos, como Cortázar, García Márquez o Lezama Lima, entre otros, que más tarde alcanzarían un prestigio internacional, o bien se organizaron números monográficos, como la entrega dedicada a la literatura erótica (un tema que no sólo está presente en la obra narrativa de Inés, sino de la mayoría de los miembros del grupo), o a las relaciones entre literatura y sociedad.

La revista también estuvo integrada por varias secciones fijas: en

36 'Talón de Aquiles’ (que sólo apareció durante la primera época), los editores criticaban y comentaban (por lo general con cierta ironía) las novedades y chismes literarios; en 1956 esta sección se hizo acompañar por 'Aguja de navegar cultos', dedicada a reseñas y notas críticas que aparecen rubricadas por sus autores. A partir de 1957, estas dos secciones fueron sustituidas por 'Actitudes', que los directores de la nueva época conservaron hasta el fin de la revista y en la cual se publicaban cartas de los colaboradores, noticias e información sobre títulos recientes (fundamentalmente literarios), además de las reseñas y críticas de cine, artes plásticas, teatro y música. Esta sección alcanzó gran fama entre el público y, de hecho, constituye una suerte de manifiesto del grupo, pues en ella los escritores que lo integraban dan (sin tapujos) sus opiniones sobre las novedades literarias, valoran la calidad de los textos comentados, o bien expresan su postura y su 'actitud' (de aquí el título de la sección) respecto a la literatura y el acontecer cultural de 
INÉS ARREDONDO

principios de la década de los sesenta. Hacia 1959 a esta sección se añadirá 'La pajarera’, de análisis y crítica textual.

Si, en parte, esta actitud crítica de los miembros de la Revista Mexicana de Literatura creó -como veremos más adelante- una serie de rencillas, enemistades y envidias en distintos sectores intelectuales de México, sirvió también de instrumento de formación y contacto entre sus colaboradores, pues -como explica Juan Vicente Melo- para todos sus integrantes hacerla fue "un enriquecimiento cotidiano de lecturas: además, trabajar en las revistas, en una editorial, es conocer a los demás a través de lo que escriben, pero en vivo, no en libro, sino en lo que van a publicar apenas". ${ }^{16}$

Respecto a las causas que motivaron el cierre de la publicación en 1965, los miembros del grupo tienen distintas opiniones. Para Juan García Ponce, el fin de la revista fue una consecuencia lógica de la actitud tan estricta que habían adoptado como criterio para la publicación de los materiales que llegaban a la mesa de redacción, pues explica: "llegó un momento en que éramos tan exigentes que ni siquiera nuestros textos eran tan buenos para ser publicados, y ya no quedaba nada verdaderamente". ${ }^{17}$ Por su parte, en la citada entrevista de Fernández Levet, ${ }^{18}$ Arredondo dice que la revista terminó porque al grupo ya no le convenía hacerla, pues a mitad de la década de los sesenta todos eran mayores, tenían hijos que mantener y habían logrado publicar en diversos medios culturales en los que sí les pagaban las colaboraciones. Además, se sabe que hacia 1965 la publicación atravesó por una crisis económica seria, factor que, sin duda, debió habitar en las mentes de sus colaboradores y, de cierta forma, sirvió de abono a la decisión de cerrarla.

Sobre quiénes eran realmente sus miembros, la lista de los autores mexicanos que durante la segunda época colaboraron con mayor frecuencia en la revista habla por sí sola: Tomás Segovia, Juan Vicente

${ }^{16}$ Ibid., p. 99.

${ }^{17}$ Ibid., p. 69.

${ }^{18}$ Ibid., p. 45. 
CLAUDIA ALBARRÁN

Melo, Huberto Batis, Inés Arredondo, José de la Colina, Salvador Elizondo, Sergio Pitol, José Emilio Pacheco y Jorge Ibargüengoitia. No obstante, en las entrevistas que González Levet hizo a Batis, Melo y García Ponce, sólo se refieren a la última época de la revista, se 'olvidan' de incluir en el grupo a Tomás Segovia ${ }^{19}$ y niegan rotundamente que Elizondo, De la Colina, Pacheco e Ibargüengoitia fueran integrantes de la revista. Dicen que los demás sólo eran amigos cercanos, que Pacheco -por ejemplo- aparecía en el consejo de redacción, pero que casi nunca iba a las reuniones de los miércoles en la Casa del Lago, al restaurant SEP's (en especial, el ubicado en la Avenida Sonora que, de alguna manera, fungía como centro de reunión del grupo) o a Peyton Place; ${ }^{20}$ que Ibargüengoitia “iba y venía; entraba y salía”21 de la revista, "pero que no fue un miembro pujante". ${ }^{22}$

Esta actitud ciertamente selectiva de los miembros del grupo -que no sólo se manifestaba en el hecho de que ellos decidían quiénes eran los integrantes de su círculo, sino en el criterio de calidad que les servía de punto de referencia para rechazar o aceptar los textos que publicarían en su revista- aunada a otros factores, como la publicidad

${ }^{19}$ En la Entrevista que Ambra Polidori le hizo a Inés, titulada "Inés Arredondo: 'La sensualidad abre el misterio y el deslumbramiento'”, Sábado, $n^{\circ}$ 38, 5 de agosto, 1978, p. 10-11, Arredondo dice que su generación se reduce a las cuatro personas que hacían la revista: García Ponce, Batis, Melo y De la Colina (ella no se incluye). Y respecto a Tomás Segovia, agrega: “querámoslo o no, Juan García Ponce, Juan Vicente Melo, José de la Colina y yo recibimos - ¿se puede decir influencia?- por lo menos de la crítica y la enseñanza de rigor de Tomás, él nos enseñó a leer de otra manera... Y no es justo que ahora se lo regateemos".

${ }^{20}$ En la entrevista que Sergio González Levet le hizo a Juan García Ponce (op. cit, p. 79), éste explica que así le llamaban al departamento de Juan Vicente Melo, pero que, en realidad, no sabe "por qué de pronto salieron esos nombres, ha de haber sido por aquello de La caldera del Diablo -dice García Ponce. Ese departamento estaba en el Edificio Condesa y era un lugar totalmente adorable".

${ }^{21}$ Ibid., p. 55.

${ }^{22}$ Ibid., p. 56. 
INÉS ARREDONDO

que los comentarios de cada uno de ellos realizó de la obra de sus compañeros de grupo en las otras revistas y suplementos culturales o el apoyo que recibieron de la industria editorial del país, provocó en varios lectores y en otros grupos literarios de la década de los sesenta una de las más fuertes críticas, ya que se afirmaba que la Revista Mexicana de Literatura -que el propio García Ponce no duda en calificar de "promiscua” - ${ }^{23}$ sólo servía como una forma de autopromoción y de autoelogio de una mafia (con toda la carga negativa que la palabra conlleva: poder, fraude, monopolio) de escritores que había venido constituyéndose como tal desde mediados del siglo con el apoyo de García Terrés y de los suplementos dirigidos por Benítez.

Y es que, además de las instituciones, de las revistas y de los suplementos culturales, las casas editoriales del momento -algunas nacidas en la década de los sesenta y otras fundadas con anterioridad-si bien desempeñaron un papel determinante en la promoción de los miembros de la Generación del Medio Siglo, en aquellos otros escritores e intelectuales aparentemente marginados del circuito editorial de alguna forma también generaron sentimientos de envidia y resentimiento contra ese puñado de jóvenes elegidos que tenían acceso a las editoriales porque gozaban de lo que se suponía eran los beneficios del poder. La lista cronológica de las fechas en las que se publicaron las obras de algunos miembros de esta generación durante la década de los sesenta habla por sí sola del apoyo que recibieron de esta industria, pero también, por qué no decirlo, de su irrefrenable productividad:

1958 Luz de aquí, de Tomás Segovia (FCE).

1959 Zamora bajo los astros, de Segovia (Imprenta Universitaria) y Ven, caballo gris y otras narraciones, de José de la Colina (Universidad Veracruzana).

1960 El sol y su eco, de Segovia (Universidad Veracruzana).

1962 Los Muros enemigos, de Juan Vicente Melo (Universidad Veracruzana); La lucha con la Pantera y El cine italiano, de

${ }^{23}$ Ibid., p. 81. 
CLAUDIA ALBARRÁN

De la Colina (Universidad Veracruzana y UNAM, respectivamente).

1963 Imagen primera y La noche, de García Ponce (Universidad Veracruzana y Ediciones Era, respectivamente).

1964 Figura de paja, de García Ponce y Fin de semana, de Melo (ambos en Ediciones Era).

1965 Cruce de caminos, de García Ponce (Universidad Veracruzana); La señal, de Inés Arredondo (Ediciones Era); Farabeuf o la crónica de un instante, de Salvador Elizondo (Joaquín Mortiz) e Infierno de todos, de Sergio Pitol (Universidad Veracruzana).

1966 La casa en la playa, de García Ponce y Los climas, de Pitol (ambos en Joaquín Mortiz); Narda o el verano, de Elizondo (Ediciones Era) y la colección de Autobiografías de cada uno de los miembros de la generación publicó Empresas Editoriales y que más tarde publicó Joaquín Mortiz bajo el título Nuevos escritores mexicanos presentados por sí mismos.

1967 Anagnórisis, de Segovia (Siglo XXI) y Morirás Lejos, de José Emilio Pacheco (Joaquín Mortiz) y No hay tal lugar, de Pitol (Ediciones Era).

1968 Desconsideraciones, Entrada en materia, Nueve pintores mexicanos y La aparición de lo invisible, de García Ponce (en Joaquín Mortiz, Imprenta Universitaria, Ediciones Era y Siglo XXI respectivamente); Historias y poemas, de Segovia (Ediciones Era) y El hipogeo secreto, de Elizondo (Joaquín Mortiz).

1969 La cabaña, de García Ponce; No me preguntes cómo pasa el tiempo, de Pacheco; El retrato de Zoe y otras mentiras, de Elizondo (los tres en Joaquín Mortiz) y La obediencia nocturna, de Melo (Ediciones Era).

Como dijimos algunas páginas antes, los miembros de esta generación también estaban directamente involucrados en la tarea editorial, 
INÉS ARREDONDO

ya fuera como dictaminadores, reseñistas, correctores de estilo o presentadores ‘oficiales' de libros que mes con mes salían a la venta en distintas casas editoriales del país. En una tesis aún no publicada en México, ${ }^{24}$ Kristine Vanden Berghe dice que la presencia de estos escritores en los círculos editoriales, aunada a la asiduidad con la que colaboraban tanto en las revistas y suplementos culturales más importantes de México (en especial, en aquellos dirigidos por Benítez), permite establecer una suerte de red propagandística y de autopromoción, la cual, desde su punto de vista, constituye la evidencia más clara de la existencia de una élite de escritores e intelectuales que integraban la supuesta mafia.

Como ella explica, el término mafia fue utilizado en estos dos suplementos por el grupo Nuevo Cine (1961) para criticar a quienes se reunían en torno a la 'capillita' del viejo cine mexicano, del cual se decía que era una "mafia de productores que señorea el cine nacional", 25 que estaba "prostituido por una mafia de ancianos codiciosos y sepultados bajo una montaña escatológica de tangos, fichadoras, charros, vampiros y tintanes" ${ }^{26} \mathrm{El}$ término -empleado por los propios colaboradores de estos dos suplementos para referirse a viejos monopolios relacionados con la actividad cinematográfica de México- será utilizado más tarde por otros escritores e intelectuales para reprocharle a los miembros de la Revista Mexicana de Literatura y a los colaboradores de esos dos suplementos culturales su actitud cerrada, de cuatachismo que ellos mismos habían criticado en otros.

En 1964 se publicó en "La Cultura en México" un texto de Luis Guillermo Piazza que lleva por título "En torno a la sátira y la parodia”, 27 en el que sugiere la creación de un boletín que, 'burla burlando',

${ }^{24}$ Presentada en la Facultad de Filosofía y Letras para optar por el grado de Maestra en 1981, titulada La cultura en México (1959-1972) en dos suplementos: 'México en la Cultura', de Novedades y 'La Cultura en México', de Siempre!

${ }^{25}$ En "La Cultura en México", n 6, p. 20.

${ }^{26}$ En "La Cultura en México", n² 23, p. 1.

${ }^{27}$ En “La Cultura en México”, n 136, p. 13. 


\section{CLAUDIA ALBARRÁN}

recree y reproduzca el ambiente de las camarillas culturales del México de los años sesenta. Vander Berghe dice que a partir de este texto (ciernes de lo que sería el libro La Mafia, publicado por Piazza en 1967), “empezarían a proliferar artículos irónicos y autoirónicos sobre la mafia, los cuales tejen paulatinamente una mitología en torno a ella”. Y agrega: “es sobre todo Piazza, más que Monsiváis, el que propaga la imaginería mafiosa”. ${ }^{28}$

Lo que, sin embargo, Vanden Berghe no dice en su trabajo es que gracias a este grupo de mafiosos fue posible que otros jóvenes talentosos no sólo publicaran por primera vez sus obras de creación y sus ensayos, sino que en México se leyeran (también por primera vez) a autores europeos, norteamericanos o latinoamericanos que de otra forma quizá no se hubieran conocido en nuestro país. Lo mismo podemos decir del esfuerzo de difusión, traducción y crítica que la Generación del Medio Siglo hizo posible y que, de hecho, tuvo como propósito central fomentar la calidad literaria, el diálogo lúcido y racional entre los escritores e intelectuales jóvenes y los consagrados. Enrique Krauze piensa que este esfuerzo generacional es sólo similar "al intento de apropiación que Vasconcelos, Reyes y Paz” hicieron de nuestra cultura décadas atrás y que la "lista de temas, influencias y técnicas literarias que ellos asimilan y recrean" no sólo fue inmensa, sino que incluso influyó en la producción literaria de otras provincias. ${ }^{29} \mathrm{Y}$, en su defensa, Gustavo García opina que a esa generación correspondió

(...) un auge editorial inimaginable, la creación de editoriales ahora indispensables, la proliferación de revistas literarias y suplementos, la poligrafía, la disciplina del lector y del escritor unidos en un solo goce. (...) El panorama de esa generación es cada día más deslumbrante, su manera de revisar e imponer con tonos nuevos los trucos del lenguaje, las trampas de la narración, la mirada limpia para contar un país

${ }^{28}$ En Kristine Vanden Berghe, op. cit., p. 52.

${ }^{29}$ Enrique Krauze, art. cit., p. 152. 
INÉS ARREDONDO

inédito, una generación que ya no podía hablar con las palabras de los narradores anteriores le hace parecer una generación de individualidades muy semejantes o de grupos muy homogéneos de calidad con raíces inexplicables. ${ }^{30}$

Respecto a la constitución de este grupo como una mafia, Armando Pereira señala lo siguiente:

Si analizáramos con distancia crítica el panorama actual de la literatura mexicana, ¿no podríamos hablar también de ‘mafias’ muy precisas y delimitadas? Una de dos: o aceptamos que en nuestro ámbito cultural la ‘vocación mafiosa’ es un mal endémico que nos constituye y contra el que ya nada podemos hacer, o aceptamos, más bien, que toda revista o grupo literario tiene derecho a tejer su propia red de afinidades y divergencias sin que por ello se sienta culpable o en pecado mortal. ¿No se ha dicho lo mismo, por otra parte, de grupos como el de Sur en Buenos Aires o el de Orígenes en La Habana, para citar dos ejemplos cercanos en el tiempo y en el espacio? ${ }^{31}$

La mala fama que giró en torno a los miembros de esta generación, los chismes y los rencores que sus enemigos llegaron a acumular contra ellos coincidieron con la salida de García Terrés como director de Difusión Cultural de la UNAM en 1966 y con la entrada de Gastón García Cantú en 1967, quien pidió a Melo su renuncia a la Casa del Lago; esto hizo que los miembros de la generación y un grupo importante de intelectuales manifestaran su indignación en distintos medios culturales y periodísticos y, a su vez, fueran obligados a renunciar a la revista Universidad de México, a la Imprenta Universitaria y a otros

\footnotetext{
${ }^{30}$ En “Inés Arredondo: Dueña inconsciente de un mundo perfecto”, Sábado, 11 de noviembre, 1989, p. 10.

${ }^{31}$ Op. cit., p. 42-3.
} 
CLAUDIA ALBARRÁN

organismos e instituciones culturales universitarios en los que habían tenido un papel destacado.

Basado en los comentarios de Huberto Batis, Armando Pereira nos ofrece una crónica detallada de las causas y consecuencias de la ruptura de los miembros de esta generación con Gastón García Cantú. Cito in extenso sus palabras:

El detonante que hizo explotar la bomba fue el asesinato de un homosexual italiano en la Facultad de Filosofía y Letras. Huberto Batis se ha referido a ese acontecimiento como el inicio de las hostilidades: "Había habido además por esos días -señala Batis- un crimen de un homosexual, de la Facultad de Filosofía y Letras, un italiano. Entonces, se vieron envueltas en él todas las gentes que estaban en una agenda del italiano, y en esa agenda estábamos todos, pues todos lo conocíamos." Sin embargo, fue una la figura que pasaría a convertirse de pronto en el centro de las hostilidades, en el chivo expiatorio de una situación que no tenía que ver directamente con él: Juan Vicente Melo, al tratar vilmente de involucrarlo en el crimen. El grupo cerraría filas en torno a Melo y decidiría enfrentarse al grupo de García Cantú. El desenlace no se hizo esperar: de una manera sutil, como generalmente suele ocurrir en estos casos, se les obligó a todos ellos a renunciar a sus puestos en la Universidad y de un día para otro se vieron en la calle, sin trabajo. Una vez más, una situación de carácter personal o íntimo vuelve a convertirse en el vehículo de intenciones políticas o culturales más bien oscuras. “Tocó al nacionalismo ramplón, demagógico y populista -concluye Batis- intentar destripar a mi gente de letras. (...) [En] aquellos tiempos oscuros del abyecto diazordacismo, en aquel río revuelto, Gastón García Cantú implantó, desde Difusión Cultural de la Universidad Nacional, la represión de todo arte, literatura y pensamiento crítico que no se ocupara en contarle las lentejuelas a la china poblana.” 
INÉS ARREDONDO

Es decir, -continúa Pereira- para truncar la creciente fuerza que cobraba en la escena nacional una corriente amplia, plural y abierta al arte y a la literatura de todas las latitudes, no pudieron más que valerse de medios pequeños y sucios, pues por lo visto no contaban con argumentos suficientes en el terreno en el que por principio debía haberse dirimido el conflicto: el terreno de la cultura. ${ }^{32}$

Lo que vino después, lo conocemos: El movimiento del 68 -que, como explica Batis, encontró a los miembros del grupo 'voluntariamente marginados'-, ${ }^{33}$ el auge que comenzó a cobrar en nuestro país la literatura de la onda y otra serie de hechos no menos significativos agravarían la situación de los miembros de esta generación, situación que puede resumirse en una frase de Juan García Ponce: “todos fueron aplastados por las crisis personales". ${ }^{34}$ Batis permaneció dos o tres años más en la dirección de la Revista Bellas Artes, uno de los pocos refugios que -tras el pleito con García Cantú- encontraron los miembros de la Revista Mexicana de Literatura; algunos de ellos (como Arredondo, Melo, García Ponce y el propio Batis) trabajaron también (un año, a lo sumo) en el Departamento de Cultura del Comité Olímpico Méxicano (1968).

Hacia 1970, sin embargo, las reuniones, las comidas y las fiestas que habían servido de pretexto para la discusión y el encuentro entre los integrantes de la generación se hicieron cada vez menos concurridas. A excepción de Juan García Ponce -que no abandonó la ciudad y se refugio con su enfermedad (arterioesclerosis) en su casa de Coyoacán-, varios sufrieron lo que Juan Vicente Melo ha llamado "un acto de canibalismo”: ${ }^{35}$ Inés Arredondo regresó a Culiacán tras sufrir una

${ }^{32}$ Ibid., p. 44-5.

${ }^{33}$ En Huberto Batis, “Inés Arredondo: Río subterráneo”, Sábado, n 892, 5 de noviembre, 1994, p. 3.

${ }^{34}$ En Sergio González Levet, op. cit., p. 85.

35 Véase: Rose Corral y Claudia Albarrán , “Conversación con Juan Vicente Melo”, en Universidad de México, n 482, marzo de 1991, p. 46. 


\section{CLAUDIA ALBARRÁN}

segunda crisis psicológica que esta vez la llevó a internarse en un hospital psiquiátrico, y más tarde, consiguió trabajo como maestra de literatura en un CCH. Huberto Batis, después de padecer lo que en su libro Lo que "Cuadernos del Viento" nos dejó llama 'tocar fondo', 36 viajó al extranjero y a su regreso a la Ciudad de México ocupó, junto con Arredondo, un puesto de maestro de literatura en el mismo CCH y en la Facultad de Filosofía y Letras de la UNAM. Tras la publicación de La obediencia nocturna (1969), Juan Vicente Melo se autoexilió en su natal Veracruz y optó por refugiarse en el alcohol.

No obstante las crisis emocionales y de salud por las que pasó cada uno de ellos, podemos decir que, desde el ingreso de García Cantú a Difusión Cultural, todos los integrantes del grupo siguieron con sus proyectos narrativos personales, los cuales, en gran medida, comenzaron a gestarse desde finales de los años cincuenta gracias al apoyo que recibieron de las instituciones, revistas y casas editoriales que ya hemos mencionado, y cuyos resultados no han dejado de marcar a la literatura mexicana contemporánea.

${ }^{36}$ 1984, México, Diógenes, p. 178. 